\title{
Pengaruh Premedikasi Midazolam 0,04 mg/kgBB sebelum Anestesi Spinal terhadap Respons Tubuh Saat Insersi Jarum Spinal dan Kepuasan
}

\author{
Anna Christanti, Ezra Oktaliansah, Indriasari \\ Departemen Anestesiologi dan Terapi Intensif \\ Fakultas Kedokteran Universitas Padjadjaran/RSUP Dr. Hasan Sadikin Bandung
}

\begin{abstract}
Abstrak
Conscious sedation pada pasien yang dilakukan tindakan anestesi spinal membuat pasien menjadi lebih nyaman, kooperatif selama penyuntikan, dan mengurangi respons tubuh saat insersi jarum spinal. Midazolam memiliki efek ansiolitik, sedatif-hipnotik, amnesia, melemaskan otot, dan mengurangi mual-muntah akibat pembedahan. Tujuan penelitian ini mengetahui pengaruh premedikasi midazolam 0,04 $\mathrm{mg} / \mathrm{kgBB}$ yang diberikan 30 menit sebelum dilakukan anestesi spinal terhadap respons tubuh pasien saat insersi jarum spinal dan kepuasan pasien terhadap anestesi spinal. Penelitian dilakukan periode September-Desember 2019 di RSUP Dr. Hasan Sadikin Bandung. Penelitian bersifat prospektif eksperimental menggunakan uji klinis acak buta ganda terhadap 46 subjek yang dibagi acak ke dalam 2 kelompok, yaitu kelompok kontrol (kelompok K, n=23) dan kelompok premedikasi midazolam (kelompok M, n=23). Pasca- pemberian premedikasi midazolam dinilai respons tubuh pasien saat insersi jarum spinal menggunakan prick response score dan kepuasan pasien dengan numeric rating scale. Analisis statistik untuk respons penyuntikan dan kepuasan pasien diuji dengan uji chi-square. Hasil penelitian menunjukkan respons tubuh pasien saat insersi jarum spinal berkurang $(\mathrm{p}<0,01)$ dan kepuasan pasien meningkat $(\mathrm{p}<0,01)$ pada kelompok premedikasi midazolam. Simpulan, premedikasi midazolam $0,04 \mathrm{mg} / \mathrm{kgBB}$ yang diberikan 30 menit sebelum anestesi spinal menurunkan respons tubuh pasien saat insersi jarum spinal dan meningkatkan kepuasan pasien terhadap anestesi spinal
\end{abstract}

Kata kunci: Anestesi spinal, kepuasan pasien, premedikasi midazolam, respons tubuh saat insersi jarum spinal

\section{The Effect of Midazolam Premedication $0.04 \mathrm{mg} / \mathrm{kgBW}$ before Spinal Anesthesia to Body Response during Spinal Needle Insertion and Satisfaction}

\begin{abstract}
Conscious sedation leads to a more comfortable spinal intervention for patients, making them more cooperative as well as decreasing body response during spinal needle insertion. Midazolam has anxiolytic, hypnosis-sedative, amnesia, muscle relaxation effects and ability to reduce nausea and vomiting related to a surgery. The aim of this study was to determine the effect of $0,04 \mathrm{mg} / \mathrm{kgBW}$ midazolam premedication administered 30 minutes before spinal anesthesia on body response during spinal needle insertion and patient satisfaction. The prospective experimental study with a randomized, double blinded clinical trial approach was conducted from September to December 2019 in Dr. Hasan Sadikin General Hospital Bandung. Forty-six subjects were randomly divided into 2 groups: a control group (group $\mathrm{K}, \mathrm{n}=23$ ), and a midazolam premedication group (group $M, n=23$ ). After premedication with midazolam, the patient's body response during spinal needle insertion were evaluated using the prick response score and their satisfaction was assessed using the numeric rating scale. Statistical analysis used to analyze body response during needle insertion and patient satisfaction was the Chi-Square test. Results howed that patient's body response during spinal needle insertion were reduced $(\mathrm{p}<0.01)$ and patient satisfaction increased $(\mathrm{p}<0.01)$ in the midazolam premedication group. In conclusion, $0.04 \mathrm{mg} / \mathrm{kgBW}$ midazolam premedication administered 30 minutes before spinal anesthesia reduces patient body response during spinal needle insertion and increases patient satisfaction on spinal anesthesia.
\end{abstract}

Key words: Body response during spinal needle insertion, midazolam premedication, patient satisfaction, spinal anesthesia

Korespondensi: Anna Christanti, dr, Departemen Anestesiologi dan Terapi Intensif Fakultas Kedokteran Universitas Padjadjaran/Rumah Sakit Umum Pusat Dr. Hasan Sadikin Bandung, Jl. Pasteur No. 38 Bandung 40161, Tlpn 022-2038285 Email: annacdv81@gmail.com 


\section{Pendahuluan}

Umumnya pasien yang menjalani pembedahan mengalami berbagai derajat kecemasan. Penelitian menunjukkan $60-80 \%$ pasien merasa cemas selama periode preoperatif dan sekitar $50 \%$ sebelum tindakan blok regional. ${ }^{1}$ Perasaan cemas, gugup, dan takut sewaktu anestesi regional diakibatkan oleh lingkungan kamar operasi, bunyi-bunyian alat monitor, suction, dan peralatan operasi. ${ }^{2}$ Tindakan anestesi regional yang digunakan pada saat operasi juga merupakan prosedur yang menakutkan, menyakitkan, dan traumatik bagi pasien sehingga memengaruhi kenyamanan dan kepuasan pasien. ${ }^{1}$ Hal tersebut dapat menyebabkan kesulitan bahkan kegagalan saat melakukan anestesi regional sehingga mendorong penggunaan premedikasi pada anestesi regional. ${ }^{1,3}$

Sedasi digunakan untuk membuat intervensi anestesi regional menjadi lebih nyaman bagi pasien, membuat pasien kooperatif selama penyuntikan dan juga mengurangi respons terhadap stimulus penusukan jarum..$^{1,3}$ Sedasi yang adekuat pada anestesi spinal mampu meredakan kecemasan pasien, mengurangi stres fisiologis dan psikologis, serta meningkatkan kepuasan pasien, operator, dan anestesiolog. ${ }^{4} \mathrm{Hal}$ ini dapat meningkatkan penerimaan pasien terhadap teknik anestesi regional. ${ }^{1,4}$

Midazolam dengan dosis 0,02-0,04 mg/ kgBB intravena paling sering digunakan untuk premedikasi. ${ }^{5}$ Midazolam memiliki fungsi ansiolitik, sedatif-hipnotik, amnesia, melemaskan otot, dan mengurangi mualmuntah akibat pembedahan., ${ }^{2,5}$ Beberapa penelitian sebelumnya menunjukkan bahwa premedikasi midazolam efektif memberikan efek sedatif, ansiolitik, dan amnesia dengan efek samping yang minimal terhadap hemodinamik dan respirasi. ${ }^{1,2}$

Tujuan penelitian ini adalah mengetahui pengaruh pemberian premedikasi midazolam $0,04 \mathrm{mg} / \mathrm{kgBB}$ intravena yang diberikan 30 menit sebelum anestesi spinal terhadap respons tubuh pasien saat insersi jarum spinal dan kepuasan pasien.

\section{Subjek dan Metode}

Penelitian ini menggunakan desain analitik komparatif eksperimental, randomized double blind prospective study. Subjek penelitian adalah pasien yang menjalani operasi elektif dengan anestesi spinal mulai bulan September sampai Desember 2019 di RSUP Dr. Hasan Sadikin Bandung. Pemilihan subjek penelitian berdasar atas kriteria inklusi, yaitu pasien yang mengalami kecemasan sedang-berat berdasar atas visual analog scale for anxiety (VAS-A), usia 18-60 tahun, status fisik American Society of Anesthesiologists (ASA) kategori I-III, indeks massa tubuh $18,5-29,9 \mathrm{~kg} / \mathrm{m}^{2}$, tidak sedang mendapat obat premedikasi lain atau dalam terapi anti-ansietas, dan bersedia mengikuti penelitian serta menandatangani persetujuan (informed consent). Kriteria eksklusi adalah pasien hamil, alergi obat yang digunakan pada penelitian, malformasi spinal, dan operasi daerah abdomen. Kriteria drop out adalah pasien mengalami upaya percobaan spinal lebih dari 2 kali penusukan, atau gagal spinal, atau pasien mendapat tambahan obat sedasi selama operasi berlangsung, atau anestesi spinal dikonversi menjadi anestesi umum.

Penentuan jumlah sampel menggunakan formula perhitungan besar sampel pada penelitian analitik komparatif kategorik tidak berpasangan dan didapatkan jumlah sampel minimal 23 pasien untuk tiap-tiap kelompok penelitian. Pengambilan sampel menggunakan blok permutasi dan dilakukan randomisasi subjek ke dalam dua kelompok penelitian. Subjek penelitian dibagi menjadi dua kelompok, yaitu kelompok kontrol (K) mendapat premedikasi $\mathrm{NaCl}$ 0,9\% 2,5 cc yang diberikan 30 menit sebelum anestesi spinal dan kelompok perlakuan (M) mendapat premedikasi midazolam $0,04 \mathrm{mg} / \mathrm{kgBB}$ yang diberikan 30 menit sebelum anestesi spinal. Penelitian dilakukan di Instalasi Bedah Sentral RSUP Dr. Hasan Sadikin Bandung pada bulan September-Desember 2019 setelah mendapat persetujuan dari Komite Etik Penelitian Kesehatan RSUP Dr. Hasan Sadikin Nomor LB.02.01/X.6.5/264/2019.

Prosedur penelitian dimulai dengan 
menjelaskan kepada pasien dan mendapat persetujuan (informed consent) mengenai tindakan anestesi dan penelitian yang dilakukan. Pasien yang sesuai kriteria inklusi dijadikan subjek penelitian. Subjek penelitian kemudian dimasukkan ke dalam kamar operasi, dipasangkan monitor untuk mengukur hemodinamik dan dilaksanakan pencatatan status hemodinamik awal. Selanjutnya, pasien diberikan premedikasi sesuai kelompok perlakuan dan dilakukan pencatatan status hemodinamik dan skala Ramsay setiap 5 menit. Oksigen dialirkan 3 liter/menit melalui nasal kanul. Status hemodinamik dan skala Ramsay dinilai kembali dan dicatat sebelum melakukan prosedur spinal. Anestesi spinal dilakukan pada menit ke-30 pascapemberian premedikasi pada posisi duduk, dengan sebelumnya diberikan loading cairan Ringer laktat $10 \mathrm{~mL} / \mathrm{kgBB}$ dalam 20 menit. Insersi jarum spinal dengan jarum tipe quincke, Spinocan ${ }^{\circledR}$ 25G tanpa introducer di L3-L4. Respons tubuh pasien dinilai saat insersi jarum spinal dengan teknik median menggunakan Prick Response Score, skor 1=pergerakan tubuh pasien terlihat jelas (gross movement), skor 2=kontraksi otot punggung (back muscle contraction), skor 3 =pergerakan pasien minimal (minimal patient movement) dan skor $4=$ tidak terdapat pergerakan pasien (no patient movement). ${ }^{3}$

Parameter hemodinamik dan kedalaman sedasi dimonitor setiap 3 menit selama 15 menit pertama setelah injeksi anestesi lokal spinal dan selanjutnya setiap 5 menit sampai prosedur operasi selesai. Bila terjadi hipotensi (MAP TDS $<90 \mathrm{mmHg}$ ) atau tekanan darah turun di bawah $20-30 \%$ dari tekanan darah rerata, diberikan bolus efedrin $\mathrm{HCl} 5$ mg sampai tekanan darah kembali dalam batas normal. Bila terjadi bradikardia atau laju jantung yang kurang dari $50 \mathrm{kali} / \mathrm{menit}$ diberikan sulfas atropin $0,01-0,02 \mathrm{mg} / \mathrm{kgBB}$ intravena dengan dosis maksimal pemberian 2 mg sampai akhir operasi. Semua kejadian efek samping selama prosedur pembedahan seperti hipotensi, bradikardia, gangguan napas, dan pergerakan yang mengganggu prosedur pembedahan dicatat. Semua subjek penelitian tidak mendapatkan obat sedasi intravena selama operasi, tetapi diberikan profilaksis Postoperative Nausea and Vomiting (PONV) deksametason $10 \mathrm{mg}$ intravena.

Di ruang pemulihan, ketika pasien sudah sadar penuh, pasien ditanyakan apakah merasa lebih tenang saat dilakukan tindakan anestesi spinal, apakah merasa nyeri saat dilakukan penusukan jarum spinal, apakah mengingat prosedur anestesi spinal yang telah dilakukan, dan apakah pasien bersedia menjalani anestesi spinal lagi pada kesempatan berikutnya. Selanjutnya, berdasar atas pengalaman pasien yang telah disebutkan di atas, ditanyakan tingkat kepuasan pasien mempergunakan Numeric Rating Scale (NRS) yang terdiri atas angka 0-100. Angka 0 menunjukkan tingkat kepuasan yang paling rendah dan 100 menunjukkan tingkat kepuasan yang paling tinggi. Skala penilaian dibagi menjadi 5 interval. Skor di bawah 20 dianggap sangat tidak puas, skor 20-39 dianggap tidak puas, skor 40-59 dianggap cukup puas, skor 60-79 dianggap puas, dan $\geq 80$ dianggap sangat puas. ${ }^{6}$

Uji statistik menggunakan uji $t$ untuk data numerik, sedangkan untuk data kategorik menggunakan uji chi-square. Data hasil penelitian dicatat dan diolah menggunakan program statistical product and service solution (SPSS) versi 22.0 for windows.

\section{Hasil}

Karakteristik subjek penelitian berdasar atas usia, indeks massa tubuh, tingkat pendidikan, lama operasi, tingkat kecemasan preoperatif dan klasifikasi ASA antara kelompok kontrol (K) dan perlakuan (M) tidak terdapat perbedaan signifikan ( $p>0,05$; Tabel 1).

Prick response antara kelompok kontrol dan perlakuan terdapat perbedaan bermakna ( $p<0,01)$. Pada kelompok kontrol didominasi oleh pergerakan yang jelas terlihat dan kontraksi otot punggung, sedangkan pada kelompok perlakuan didominasi oleh tidak terdapat pergerakan pasien, pergerakan minimal dan kontraksi otot punggung (Tabel 2).

Tingkat kepuasan pasien pada kelompok 
Tabel 1 Karakteristik Umum Subjek penelitian

\begin{tabular}{|c|c|c|c|}
\hline Karakteristik Pasien & $\begin{array}{c}\text { Kontrol } \\
(n=23)\end{array}$ & $\begin{array}{c}\text { Perlakuan } \\
(n=23)\end{array}$ & Nilai p \\
\hline \multicolumn{4}{|l|}{ Usia (tahun) } \\
\hline Mean (SD) & $46,22(12,64)$ & $39,35(12,90)$ & 0,075 \\
\hline Median (min.-maks.) & $52(22-60)$ & $41(18-60)$ & \\
\hline \multicolumn{4}{|l|}{ IMT $\left(\mathrm{kg} / \mathrm{m}^{2}\right)$} \\
\hline Mean (SD) & $23,01(2,59)$ & $23,92(2,79)$ & 0,260 \\
\hline Median (min.-maks.) & $22,4(18,7-28,76)$ & $24,03(18,7-29,5)$ & \\
\hline \multicolumn{4}{|l|}{ Pendidikan } \\
\hline SD & 2 & 2 & 0,510 \\
\hline SLTP & 2 & 3 & \\
\hline SLTA & 17 & 14 & \\
\hline D3 & 1 & 0 & \\
\hline S1 & 1 & 4 & \\
\hline \multicolumn{4}{|l|}{ Lama operasi (menit) } \\
\hline Mean (SD) & $88,48(22,93)$ & $75,65(25,24)$ & 0,078 \\
\hline Median (min.-maks.) & $95(50-120)$ & $60(30-120)$ & \\
\hline \multicolumn{4}{|l|}{ Tingkat kecemasan } \\
\hline Sedang & 9 & 13 & 0,376 \\
\hline Berat & 14 & 10 & \\
\hline \multicolumn{4}{|l|}{ ASA } \\
\hline 1 & 5 & 11 & 0,090 \\
\hline 2 & 16 & 12 & \\
\hline 3 & 2 & 0 & \\
\hline
\end{tabular}

Keterangan: nilai p untuk usia, IMT, dan lama operasi diperoleh dari uji t dua kelompok independen, sedangkan untuk pendidikan, tingkat kecemasan, dan ASA diperoleh dari uji chi-square, perbedaan bermakna jika p<0,05

perlakuan lebih baik dibanding dengan kelompok kontrol dengan perbedaan yang signifikan $(\mathrm{p}<0,05)$. Analisis indikator kepuasan pasien yang dinilai berdasar atas perasaan tenang saat anestesi spinal, persepsi nyeri saat insersi jarum spinal, dan memori terhadap anestesi spinal, didapatkan lebih baik pada kelompok perlakuan dibanding

Tabel 2 Perbandingan Respons Tubuh Pasien Saat Insersi Jarum Spinal

\begin{tabular}{lccc}
\hline \multicolumn{1}{c}{ Prick Response } & $\begin{array}{c}\text { Kontrol } \\
(\mathbf{n = 2 3 )}\end{array}$ & $\begin{array}{c}\text { Perlakuan } \\
(\mathbf{n = 2 3 )}\end{array}$ & Nilai p \\
\hline Pergerakan pasien jelas terlihat & 12 & 0 & $<0,01$ \\
Kontraksi otot punggung & 11 & 3 & \\
Pergerakan pasien minimal & 0 & 7 & \\
Tidak terdapat pergerakan pasien & 0 & 13 & \\
\hline
\end{tabular}

Keterangan: nilai $\mathrm{p}$ diperoleh dari uji chi-square, perbedaan bermakna jika $\mathrm{p}<0,05$ 
Tabel 3 Perbandingan Kepuasan Pasien dengan Anestesi Spinal

\begin{tabular}{|c|c|c|c|}
\hline Variabel & $\begin{array}{c}\text { Kontrol } \\
(n=23)\end{array}$ & $\begin{array}{l}\text { Perlakuan } \\
(n=23)\end{array}$ & Nilai p \\
\hline \multicolumn{4}{|c|}{ Perasaan tenang saat dilakukan anestesi spinal } \\
\hline Ya & 0 & 20 & $<0,01$ \\
\hline Tidak & 23 & 3 & \\
\hline \multicolumn{4}{|l|}{ Nyeri saat insersi spinal } \\
\hline Ya & 23 & 5 & $<0,01$ \\
\hline Tidak & 0 & 18 & \\
\hline \multicolumn{4}{|l|}{ Ingatan akan prosedur spinal } \\
\hline Ya & 23 & 7 & $<0,01$ \\
\hline Tidak & 0 & 16 & \\
\hline \multicolumn{4}{|c|}{ Kesediaan menjalani anestesi spinal lagi } \\
\hline Ya & 20 & 23 & 0,232 \\
\hline Tidak & 3 & 0 & \\
\hline \multicolumn{4}{|l|}{ Tingkat kepuasan } \\
\hline Sangat puas & 0 & 9 & $<0,01$ \\
\hline Puas & 2 & 13 & \\
\hline Cukup puas & 21 & 1 & \\
\hline Tidak puas & 0 & 0 & \\
\hline Sangat tidak puas & 0 & 0 & \\
\hline
\end{tabular}

Keterangan: nilai p diperoleh dari uji chi-square, perbedaan bermakna jika p<0,05

dengan kelompok kontrol dengan perbedaan bermakna $(p<0,01)$. Namun, kesediaan menjalani anestesi spinal kembali tidak didapatkan perbedaan yang bermakna di antara kedua kelompok ( $>0,05$; Tabel 3).

\section{Pembahasan}

Karakteristik umum kedua kelompok berdasar atas usia, indeks massa tubuh, tingkat pendidikan, lama operasi, tingkat kecemasan, dan status fisik ASA tidak berbeda bermakna sehingga kedua kelompok dianggap homogen dan layak dibandingkan. Perbedaan usia memberikan respons fisiologis dan neuropsikologis yang berbeda pascapremedikasi midazolam. Peningkatan efek farmakologis midazolam pada usia lanjut di atas 60 tahun disebabkan oleh peningkatan sensitivitas terhadap midazolam sehingga midazolam dapat menimbulkan efek sedasi yang panjang, penurunan kardiorespirasi, dan saturasi oksigen yang lebih besar. ${ }^{7}$ Pada penelitian didapatkan kelompok usia di bawah 20 tahun memiliki tingkat kecemasan yang lebih tinggi. ${ }^{8,9}$

Perubahan fisiologis terhadap tubuh seperti penambahan jaringan lemak dapat memengaruhi distribusi, metabolisme, dan klirens obat dari tubuh. Pertimbangan yang berbeda diperlukan terhadap obat yang bersifat lipofilik dan hidrofilik karena memiliki distribusi yang berbeda pada pasien yang obesitas dan kurus. ${ }^{8,9}$ Berat badan juga memengaruhi fungsi hati dan ginjal. Volume distribusi sentral dan perifer midazolam meningkat berbanding lurus dengan berat badan. ${ }^{8}$ Pascabolus intravena dosis per kgBB, konsentrasi dalam darah menjadi lebih berkurang terhadap obat yang bersifat lipofilik seperti midazolam sehingga membutuhkan waktu lebih lama untuk mencapai kadar 
konsentrasi yang tetap, akibatnya efek midazolam menjadi lebih panjang dibanding dengan berat badan normal. ${ }^{8}$ Distribusi obat dapat berbeda akibat perbedaaan komposisi tubuh dan efek obat menjadi berkurang. ${ }^{8,9}$

Kepuasan terhadap anestesi mempunyai hubungan yang berbanding terbalik dengan tingkat pendidikan. Ekspektasi lebih tinggi terjadi pada tingkat pendidikan yang lebih tinggi. ${ }^{10}$ Literatur menyatakan pasien dengan tingkatpendidikan yang lebih tinggi mengalami kecemasan yang lebih tinggi karena kesadaran mereka terhadap komplikasi. ${ }^{11}$

Midazolam itu mempunyai mula kerja yang cepat dan durasi kerja yang pendek setelah pemberian intravena., ${ }^{2,9}$ Waktu paruh midazolam sekitar 1,9-2 jam sehingga pada operasi yang berlangsung lebih dari 2 jam, efek midazolam menjadi lebih berkurang. ${ }^{5}$ Pasien dapat merasa tidak nyaman tanpa pemberian obat sedatif lain pada operasi yang lama sehingga menurunkan kepuasan terhadap tindakan anestesi. ${ }^{4}$

Kecemasan preoperatif merupakan kondisi patologisyang kadarnya bervariasiantarpasien yang dapat mengakibatkan ketidakpuasan terhadap tindakan anestesi. ${ }^{12,13}$ Pada penelitian di Turki tahun 2014 yang meneliti tentang efek usia, jenis kelamin, status pendidikan, dan status fisik ASA terhadap kecemasan perioperatif pada pasien yang dilakukan anestesi spinal, didapatkan bahwa mayoritas pasien mengalami kecemasan yang sedang. ${ }^{12}$ Berdasar atas literatur, terdapat hubungan antara tingkat kecemasan preoperatif yang tinggi risiko tindakan sehingga diperlukan pengukuran tingkat kecemasan preoperatif. ${ }^{13}$ Pada penelitian di Mesir tahun 2016 yang meneliti premedikasi midazolam terhadap parturien yang mengalami preeklamsia dengan anestesi spinal untuk operasi sectio caesaria didapatkan hubungan antara tingkat kecemasan pasien, ketidaknyamanan saat insersi jarum spinal dan tingkat kepuasan pasien. ${ }^{14}$ Pemberian premedikasi midazolam pada pasien yang mengalami kecemasan sedang-berat dapat mengurangi kecemasan, memberi kenyamanan saat insersi jarum spinal, dan memberikan kepuasan yang lebih baik. $^{12-14}$

Status fisik ASA pada beberapa penelitian memengaruhi tingkat kecemasan preoperatif. Kecemasan preoperatif berbanding lurus dengan status fisik ASA. Hal ini disebabkan pasien dengan komorbiditas cenderung lebih cemas dibanding dengan pasien yang sehat. ${ }^{15}$

Pasien yang menjalani anestesi spinal mempunyai kebutuhan dasar terhadap implementasi teknik sedasi yang efektif, aman, hemodinamik stabil, efek samping kardiorespirasi atau mual-muntah minimal, biaya murah, mampu menyediakan ansiolitik, analgesia, dan rasa tenang. ${ }^{1}$ Pada penelitian ini sebagian besar pasien yang mendapatkan premedikasi dengan midazolam melakukan pergerakan minimal sampai tidak bergerak saat insersi jarum spinal. Penelitian ini sejalan dengan penelitian di India pada tahun 2015 yang melaporkan terdapat penurunan pergerakan pasien, sedasi tidak berlebihan, respons verbal baik, amnesia, dan kepuasan pasien pada pasien yang mendapatkan premedikasi midazolam sebelum anestesi spinal. ${ }^{3}$ Penelitian lain di Pakistan tahun 2015 menunjukkan pemberian premedikasi midazolam intravena untuk anestesi spinal memberikan efek sedatif, amnesia, dan juga mengurangi kecemasan pasien sehingga pasien menjadi lebih kondusif saat dilakukan anestesi spinal dan penerimaan pasien terhadap anestesi spinal lebih baik. ${ }^{16}$

Midazolam yang diberikan secara intravena sebagai obat premedikasi akan berikatan dengan reseptornya di antara subunit $\alpha 1,2$, 3 , 5, dan subunit $\gamma$ sehingga menghasilkan efek sedatif dan amnesia. Midazolam yang berikatan dengan reseptornya pada subunit $\alpha 2$ memberikan efek ansiolitik dan relaksasi otot, sedangkan yang berikatan dengan $\alpha 3$ dan $\alpha 5$ memberikan efek relaksasi otot. ${ }^{17}$ Midazolam juga menghasilkan analgesia neuraksial dengan memengaruhi reseptor asam amino gama butirat $\left(\mathrm{GABA}_{\mathrm{A}}\right)$ yang secara selektif dilewati oleh ion klorida, menyebabkan hiperpolarisasi membran sinaptik dan inhibisi transmisi saraf sehingga menimbulkan efek antinosiseptif dengan mengurangi hipereksitabilitas dari medula spinalis. ${ }^{17,18}$ Midazolam juga memiliki 
efek inhibisi terhadap pelepasan kortisol dan mengurangi respons stres. ${ }^{14}$

Tingkat kepuasan pasien lebih tinggi terhadap anestesi spinal pada kelompok perlakuan itu disebabkan oleh pengaruh premedikasi midazolam itu yang membuat perasaan pasien menjadi lebih tenang saat dilaksanakan anestesi spinal, persepsi nyeri pasien menjadi lebih berkurang saat insersi jarum spinal, dan efek amnesia terhadap prosedur spinal yang sudah dilakukan.

Pengaruh midazolam yangberikatan dengan reseptor pada subunit $\alpha 1$ dan $\alpha 2$ terlihat pada kelompok perlakuan yang sebagian besar merasa lebih tenang saat dilakukan anestesi spinal. ${ }^{17}$ Hal ini sesuai dengan penelitian di Turki dan Arab Saudi pada tahun 2011 dan 2012 bahwa premedikasi midazolam dengan dosis $\geq 0,04 \mathrm{mg} / \mathrm{kgBB}$ memberikan efek sedasi yang adekuat dengan efek samping minimal terhadap hemodinamik dan respirasi. ${ }^{19}$

Persepsinyeri saat insersi jarum spinallebih berkurang pada kelompok perlakuan karena midazolam bekerja menurunkan ambang persepsi nyeri dengan jalan menghasilkan sedasi, menyebabkan amnesia, dan bersifat ansiolitik yang mampu mengurangi komponen emosional nyeri. Ansietas dan nyeri sangat berhubungan sehingga ansietas dapat menimbulkan eksaserbasi nyeri. ${ }^{9}$

Penelitian di Jepang pada tahun 20132014 mengenai kebutuhan dosis premedikasi midazolam bergantung pada usia pasien untuk menghapus ingatan akan nyeri vaskular yang ditimbulkan oleh pemberian propofol, diketahui pemberian premedikasi midazolam memberikan efek concious sedation dan amnesia terhadap memori rasa nyeri yang ditimbulkan oleh penyuntikan propofol kontinu. ${ }^{7}$ Hal ini sesuai dengan penelitian sebelumnya pada tahun 1998 yang meneliti tentang efek pemberian premedikasi midazolam terhadap memori penyuntikan jarum spinal, didapatkan gangguan terhadap memori jangka pendek akan persepsi nyeri saat insersi jarum spinal. ${ }^{7}$ Penelitian di India pada tahun 2017 yang meneliti tentang perbandingan efek pemberian infus dexmedetomidine dan midazolam terhadap efek psikomotor, memori dan efek samping lainnya selama anestesi spinal, didapatkan premedikasi midazolam dosis $0,04 \mathrm{mg} /$ kgBB memberikan efek amnesia anterograd tanpa gangguan fungsi psikomotor ataupun depresi kardiovaskular dan respirasi. ${ }^{20} \mathrm{Hal}$ ini sesuai dengan hasil penelitian pada kelompok perlakuan yang mendapatkan premedikasi midazolam 0,04 mg/kgBB sebelum dilakukan anestesi spinal mengalami amnesia. Efek amnesia anterograd dengan premedikasi midazolam pada penelitian ini membuat pasien lupa tentang memori yang menakutkan dan kurang nyaman saat dilakukan prosedur spinal dan pembedahan sehingga tidak menimbulkan efek traumatik terhadap anestesi spinal. ${ }^{16}$

Pada penelitian ini didapatkan kesediaan pasien pada kedua kelompok untuk menjalani anestesi spinal lagi tidak berbeda bermakna. Pada kelompok kontrol, didapatkan mayoritas pasien mengalami tingkat kepuasan yang lebih rendah, namun bersedia menjalani anestesi spinal kembali. Hal tersebut dapat disebabkan oleh kelebihan yang ditawarkan anestesi spinal dibanding dengan teknik anestesi lain bahwa pasien lebih cepat kontak dengan keluarga, dapat makan lebih cepat pascaoperasi, tidak ada gangguan kardiorespirasi, waktu bangun pasien lebih cepat tanpa merasa pusing dan mual, serta analgesia pascaoperasi baik. ${ }^{1,4}$ Selain itu, pasien bersedia dilakukan anestesi spinal kembali bila memang teknik anestesi spinal adalah teknik anestesi yang dibutuhkan untuk memfasilitasi operasi. Hal ini sesuai dengan penelitian di Ethiopia pada tahun 2015 yang meneliti tentang kepuasan maternal pascaoperasi sectio caesarea dengan anestesi spinal. Pada penelitian itu didapatkan pasien yang mengalami ketidakpuasan terhadap anestesi spinal, tetapi masih bersedia menjalani anestesi spinal kembali pada kesempatan berikutnya, apabila teknik anestesi spinal tersebut diperlukan. ${ }^{10}$

Kepuasan pasien yang meningkat pada pemberian premedikasi midazolam sejalan dengan penelitian yang dilakukan di Mesir tahun 2014-2015 yang meneliti efek premedikasi midazolam terhadap kecemasan 
preoperatif, hemodinamik perioperatif dan kepuasan pascaoperatif pasien hamil dengan preeklamsia yang dijadwalkan untuk operasi sectio caesaria elektif menggunakan anestesi spinal yang diberikan 30 menit sebelum dilakukan anestesi spinal didapatkan tingkat kecemasan yang lebih rendah, perbaikan kondisi hemodinamik preoperatif dan tingkat kepuasan pascaoperatif yang lebih tinggi, tanpa efek samping terhadap bayi. ${ }^{14}$

Padapenelitian diKolumbiatahun2013yang meneliti efikasi 3 panduan sedasi pada pasien yang menjalani anestesi spinal didapatkan semua pasien yang menerima premedikasi ansiolitik bersikap kooperatif saat dilakukan insersi jarum spinal dan menyatakan tidak takut untuk menjalani anestesi spinal kembali. Pada penelitian tersebut tidak terdapat pasien yang mengalami gangguan kardiorespirasi maupun komplikasi mual-muntah sehubungan dengan penggunaan concious sedation. Walaupun dari hasil penelitian masih terdapat pasien yang mengalami withdrawl reflex dan nyeri saat insersi jarum spinal dengan pemberian premedikasi midazolam tunggal tanpa dikombinasi analgetik yang lain, namun didapatkan kepuasan pasien tinggi secara statistik. ${ }^{1}$

Keterbatasan pada penelitian ini adalah indikator untuk pengukuran kepuasan pasien hanya terbatas pada beberapa pertanyaan, sedangkan kepuasan merupakan hal yang bersifat subjektif dan mempunyai cakupan area yang luas.

\section{Simpulan}

Pada penelitian ini, premedikasi midazolam $0,04 \mathrm{mg} / \mathrm{kgBB}$ intravena yang diberikan 30 menit sebelum anestesi spinal mampu menurunkan respons tubuh saat insersi jarum spinal dan meningkatkan kepuasan pasien terhadap anestesi spinal.

\section{Daftar Pustaka}

1. Guerrero FJB, Camargo DG, Romero RP, Bustos WL, Clason ER. A Comparative analysis of 3 sedation guidelines for patients undergoing subarachnoid anesthesia. Randomized, single blind clinical trial. Rev Colomb Anestesiol. 2015;43(2):122-8.

2. Neeru B, Hardip S, Pal AJ, Lipsy B, Sukhman K. Comparison of midazolam versus clonazepam as premedication scheduled for elective abdominal hysterectomies. Int J Med Res Rev. 2016;4(8):1330-4.

3. Kumar VRH, Athiraman UK, Jahagirdar SM, Sripriya R, Parthasarathy S, Ravishankar M. Comparison of efficacy of three subanesthetic doses of ketamine in allaying procedural discomfort during establishment of subarachnoid block: a randomized double-blind trial. Saudi J Anaesth. 2015;9(1):55-9.

4. Zencirci B. Midazolam in spinal anaesthesia-intrathecal or intravenous? Dalam: Whizar-Lugo VM, penyunting. Topics in spinal anaesthesia. Intech Open. 2014;2014:123-37.

5. White PF, Eng MR. Intravenous anesthesia. Dalam: Barash PG, Cullen BF, Stoelting RK, Cahalan MK, Stock MC, Ortega R, penyunting. Clinical anesthesia. Edisi ke-7. Philadelphia: Wolters Kluwer-Lippincott Williams \& Wilkins; 2013. hlm. 905-12.

6. Mui WC, Chang CM, Cheng KF, Lee TY, Ng KO, Tsao KR, dkk. Development and validation of the questionnaire of satisfaction with perioperative anesthetic care for general and regional anesthesia in taiwanese patients. Anesthesiology. 2011;5(114):1064-75.

7. Boku A, Inoue M, Niwa H. Effective dosage of midazolam to erase the memory of vascular pain during propofol administration. Anesth Prog. 2016;63(3):147-55.

8. Anderson, B. Midazolam and how physiologic changes in the elderly patient's body lead to adversed effects. 2018 [diunduh 11 Mei 2020]. Tersedia dari: https://www.digitalcommons. assumption.edu.

9. Jun J, Han J, Choi A, Kim YJ, Lee JW, Kim DY, dkk. Adversed events of conscious sedation using midazolam for gastrointestinal endoscopy. APM. 2019;14:401-6. 
10. Idris M, Weldegiorgrs GG, Tesfamariam EH. Maternal satisfaction and its associated factors toward spinal anesthesia for caesarean section: a cross-sectional study in two Eritrean hospitals. Anesthesiol Res Pract [Online Journal] 2020 [diunduh 8 Mei 2020]. Tersedia dari: https://doi. org/10.1155/2020/5025309.

11. Maheshwari D, Ismail S. Preoperative anxiety in patients selecting either general or regional anesthesia for elective cesarean section. J Anaesthesiol Clin Pharmacol. 2015;31(2):196-200.

12. Mingir T, Ervatan Z, Turgut N. Spinal anesthesia and perioperative anxiety. Turk J Anaesth Reanim. 2014;42:190-5.

13. Kanto J. Preoperative anxiety. 2012 [diunduh 8 Mei 2020]. Tersedia dari: https://www.link.springer.com.

14. Mokhtar AM, Elsakka AI, Ali HM. Premedication with midazolam prior to cesarean delivery in preeclamptic parturients : a randomised controlled trial. Anesth Essays Res. 2016;10(3):631-6.

15. Woldegerima YB, Fitwi GL, Yimer HT, Hailekiros AG. Prevalence and factors associated with preoperative anxiety among elective surgical patients at university of Gondar hospital. Int J Surg. Open. 2018;10:21-9.

16. Sharif A, Naqvi SEH, Khan A. Conscious sedation in spinal anesthesia: a comparative study of propofol versus midazolam. KMUJ. 2017;9(1):15-8.

17. Matsuura N. Muscle power during intravenous sedation. JDSR. 2017;53:12533.

18. Mowafi HA. Spectral entropy as an objective measure of sedation state in midazolam-premedicated patients. Saudi J Anaesth. 2012;6(2):131-5.

19. Eren G, Cukurova Z, Demir G, Hergunsel O, Kozanhan B, Emir NS. Comparison of dexmedetomidine and three different doses of midazolam in preoperative sedation. J Anaesth Clin Pharmacol. 2011;27(3):367-72.

20. Savant KB, Patel H, Patel V. Sedation during spinal anaesthesia: a comparison between dexmedetomidine and midazolam infusion. IJBAR. 2017;8(05):228-32. 